\title{
ASSESSING THE INSIGHTS ON EXPERIENTIAL LEARNING USING THE AUGMENTED REALITY EXPLORATION
}

\author{
Fadzidah Abdullah $^{1 \star}$, Mohd Hisyamuddin Kassim² ${ }^{2}$ Aliyah Nur Zafirah Sanusi ${ }^{3}$, \\ Mohd Raziff Abd. Razak
${ }^{1}$ Assoc. Prof. Dr., International Islamic University Malaysia, MALAYSIA, fadzidah@iium.edu.my
${ }^{2}$ Mr., Multimedia University Malaysia, MALAYSIA, mhisyamk@gmail.com
${ }^{3}$ Asst.Prof. Dr., International Islamic University Malaysia, MALAYSIA, aliyah@iium.edu.my \\ ${ }^{4}$ Mr., University Kuala Lumpur British Malaysian Institute, MALAYSIA, mraziff@unikl.edu.my
}

\begin{abstract}
In the tertiary educational setting, learning is often taken place in a classroom environment that is too formal. Thus, to break the norm and to make learning enjoyable, exploration of a new method of knowledge dissemination using Augmented Reality (AR) was experimented in the teaching and learning of steel construction in architectural education. This exploration is intended to initiate an active learning and enjoyable environment for students at the university level. Hence, this paper examines students' insights on their experiences of AR exploration, where they actively learn through playing, experimenting, socialising and collaborating with their peers. During the learning process, students produced virtual steel construction details models, and then visualised the models through AR application that shows an interface with real time and real space. Prior to the AR exploration, students went through a series of workshops where they collaboratively developed models of steel construction details, based on their completed research. Students' feedback was sought after they completed the projects, particularly on their impression towards the project. The collected data was in the format of verbatim, obtained by having open-ended questionnaires. The data would be analysed using qualitative methods of content analysis using atlas.ti software. The generated frequency of coded factors would be quantified to produce an empirical result. Most students positively gave feedback that the new method applied for learning is effective and exciting, and they suggested the same approach should be implemented to other courses in the architectural educational program.The AR application had also offered them to have very practical and economical techniques of active learning, with the merger of ICT and online conveniences.
\end{abstract}

Keywords: Augmented Reality; Building Construction; Active Learning, Experiential Learning, Constructivism Theory, Learning by Doing, Architectural Education.

\section{INTRODUCTION}

Recent learning trends generally focus on effective learning techniques via the usage of Information and Communication Technology (ICT). The conventional pedagogical method of listening to a lecture is considered a thing of the past, although still very much relevant to today's knowledge dissemination. Hence, almost all disciplines of education are moving towards the application of e-learning and ICT techniques to remain relevant and to inspire learning eagerness among students in the tertiary educational setting. To further break the norm and to make learning enjoyable, exploration of a new method of knowledge dissemination using Augmented Reality (AR) was experimented in the teaching and learning of steel 
construction in architectural education. This exploration is intended to initiate an active learning and enjoyable environment for students at the university level.

The research is conducted to explicate students' insight into their learning experience of using Augmented Reality (AR) application for building construction class. Students' insight was sought in term of their learning experience. Survey with two (2) open-ended questions were distributed to students to express their opinions on learning experience that they have had during building construction class, which focuses on the subject of steel construction. The question also addressed students to express their opinion on the measure of improvement to be done for the effective learning experience. Feedback on their perspicacity is obtained and organised into numerical and understandable data display, using qualitative data processing software. The findings are descriptive and would be presented in graphic form for ease of understanding.

\section{CHALLENGES OF TEACHING BCM}

Building Construction and Material (BCM) course in architecture education usually requires hands-on experience, so that students could effectively learning. However, most of the time, hands-on experience of constructing a building may not be feasible for reasons that it incurs a cost, acquires energy, entails a long time, and requires real project construction setting. Thus, teaching instructors always resolve the problem by teaching in a passive classroom environment by merely giving lecturers and showing examples of construction works.

With the advancement of Information and Communication Technologies (ICT), techniques of teaching and learning have been improved tremendously. Availability of online materials, such as audios and videos, have enhanced education into a different level, that students could learn without face to face interaction with their teachers. ICT, with its virtual representations, may offer visual and auditory learning capacity, yet not all students are capable of learning effectively using either visual or auditory mechanism only. Some of them have a strong tendency to learn effectively using kinesthetic techniques, including learning by doing. Hence, a question arises of what is the most effective way for students to learn building construction in architecture education that may resemble the quality of hands-on experience?

The answer to such a question may rely on the understanding of how students learn. Henceforth, the method of teaching should tackle the issue of enriching students with their specific learning styles. Each student individually may have a strong inclination to a particular mechanism in one environment, and then has different inclination when the environment change. Therefore, the teaching method should have a combination of all aspects of learning style at a time. Scholars have outlined that learners come in a variety of learning styles, named as the VARK instrument. The VARK instrument describes the learning preferences based on the sensory modalities; visual, auditory, read-write, and kinesthetic (Rahman et al., 2017).

Besides, to be more effective, learning should be conducted in an environment where students do not realise that they are learning; instead, they feel that there are playing. Here comes the importance of interaction, either face to face or virtual interaction, or the combinations of both. The effort to have learning interesting and enjoyable could be made by providing what students currently like, interacting in social networking. Hence, they could have a creative, integrative, interactive, and effective learning experience with blended learning.

\subsection{The Current Learning Trends}

Beside clutching to students' learning styles, academicians in higher learning institutions should also grasp the current learning trends to remain relevant. The latest evolution of learning trends involves infinite terminologies related to ICT, that grow as fast as digital and e-technologies themselves. The flipped classroom, blended learning, technology-enhanced active learning (TEAL), social learning, badges, and gamification are among the terms that have high hype in the current scholarly discourses. Endeavouring to amalgamate students' learning styles and current learning trends in instructional design means fabricating relevant activities that catch students' engagements and induce active learning. Activities enhance students' experience, either through having collaborative learning, which encourages social interaction and communication or having personalised learning that develops the skill of continuous learning.

The advent of digital technology has invaded the classroom setting into having mix-mode teaching and learning techniques (Abdullah, et al., 2018). Besides, easy access to the internet enables the sharing of learning content, and this scenario has become the most powerful approaches in education. The social media platforms, such as Facebook, Google+, YouTube, Instagram, interest, and Tumblr, allow both educators and students to share, discuss and work collaboratively without depending on situated time and place. 


\subsection{Social-Media and Education}

The advancement of the mobile computing device (MCD) and the availability of social media offer a horizon of fantastic opportunities for the enhancement of learning among students. Educators could use the notions as tools for instructional strategy (Sharples, et al., 2010), simultaneously provide students with flexibility, mobility, and reachability in gaining knowledge. The application of MCD also fulfil the demands of current students' learning style and trends in higher learning institutions.

The usage of social media in tertiary learning context promotes engagement of students with constant connectivity, encourages collaborative learning, and allows mobility on authentic learning. This concept of learning also permits students to communicate with their peers and educator at any time and any place (Greenhow, 2011). The students are also allowed to explore, identify, manipulate and analyse the learning content, and in due course, they would be able to adapt the new learning trends into students' tasks (Shuler, 2009) of any kind. The experience of having integrative learning mechanisms encourage students to generate content for collaborative activities, using applications such as wiki, blogs, and social bookmarking tool. This scenario has been termed as collective intelligence (Brown, 2005), where a participatory and friendly environment is established for the growth of new ideas in cyberspace.

As social media is closely related to mobile devices, students could fully utilise the mobile platform for collaboration, discussion, and construction of their learning content (Levy, 2001). These mobile devices technologies and social media are undoubtedly capable of supporting collaborative learning. In fact, the constructivist method of learning (Pang, 2010) is implemented when students start to develop their learning content; such as producing audio-visual, taking photographs, geotagging, microblogging, responding to message, and accessing to social networking, for interaction and communication with other students or educators (Cochrane and Bateman, 2010). Hence, social media develops not only collaborative learning but also promote personalised and authentic learning, where students produce the latest content that could be used by the successive cohorts of students.

\subsection{Potential of Augmented Reality}

Augmented Reality (AR) could be defined as a technology which allows the overlaying of computergenerated objects into the real-time environment (Vavoula, et al., 2009). This technology becomes a buzzword in education because it is user-friendly and does not require expensive or sophisticated equipment. Today, mobile devices such as smartphone, tablet, and HMD are widely used by educationists in exploring the potential of AR in the educational setting (Azuma, et al., 2001). Scholars and educationists recognise that $A R$ technology has the potential to improve learning effectiveness and to learn cognitive experiences. In facts, with exciting learning experiences, AR application increases students' motivation, engagement, and satisfaction (Cheng and Tsai, 2013).

In architecture education, AR could be used to interfacing the actual and virtual environments, to produce the overlaying, or augmentations, of architectural representations. AR enables visualisation of the real world coexists seemingly with digital information. Accordingly, AR derives another term called Mobile Augmented Reality (MAR) to precisely describe the usage of mobile equipment to visualise AR objects (Kassim, et al., 2018). MAR technology is a breakthrough application that could be implemented in not only the architectural field but also in other areas, especially those that require visualisation of objects. MAR technology application is promising to be applied in all areas of study because of its practicality, user-friendliness and adaptive capability (Sanusi, et al., 2018).

\section{RESEARCH METHODOLOGY}

The need to make learning enjoyable has inspired researchers to formulate an instructional design that entails students to participate actively in the development of their learning contents and to hold responsible for their learning. In doing so, teaching instructors have to plan the learning programs and use various active teaching techniques; such as interactive lecture, demonstration, in-class discussion, virtual discussion via social media, and gamification. In addition, the idea is rationalised by deploying MAR technique and application, as tools in assisting students learning process and experiences.

First, students are required to explore the usage of $A R$, and to develop their virtual reality (VR) 3D-models of construction details of chosen buildings that used steel as the primary construction materials. The developed VR models are then converted into AR models, and all these learning content are stored in a cloud database, so that they would be easily accessible via QR code link. These AR models could be visualised in the real-time environment through an AR display technique. The students are capable of personalising their learning content as well as to navigate the AR models by using Natural User Interface (NUI). 
Second, students held an exhibition where they could demonstrate to their peers the learning content that they have developed. The presentation and demonstration were conducted in an informal outside classroom environment. For visualisation, students would have to scan the QR code and download the AR models files into their mobile storage. Then, the mobile camera will track the AR marker and generate interfaced view of the steel construction model in the real-time environment.

Third, students perception was sought in term of their learning experience. Survey with an open-ended question was distributed to students to express their opinions on learning experience that they have had during building construction class, which focuses on the subject of steel construction. Feedback on their perspicacity is obtained and organised into numerical and verbatim data display, using qualitative data processing software. The findings are descriptive and would be presented both in the table and graphic forms for ease of understanding. As shown in Table 1, the research establishes the following Modules of the Instructional Design, for the course of Building Construction and Materials.

Table 1 Modules of the Instructional Design

\begin{tabular}{|c|c|c|c|}
\hline No & Modules & Duration & Components \\
\hline 1 & Seminar & 1 Week & $\begin{array}{l}\text { 1. AR lectures, } \\
\text { 2. 3D modelling and AR demonstration } \\
\text { 3. Assignment briefing } \\
\text { 4. Group assignments (3-4 students), } \\
\text { 5. Case studies consultation }\end{array}$ \\
\hline 2 & Workshop 1 & 1 Week & $\begin{array}{l}\text { 1. 3D modelling and AR demonstration } \\
\text { 2. Progress consultation, } \\
\text { 3. Demonstrate the students progress works }\end{array}$ \\
\hline 3 & Workshop 2 & 2 Week & $\begin{array}{l}\text { 1. Progress consultation, } \\
\text { 2. Demonstrate the students' progress works, } \\
\text { 3. Create an AR Marker \& Generate QR Code, } \\
\text { 4. Exporting AR modelling for the mobile format, } \\
\text { 5. Explore and experience the AR model via } \\
\text { smartphone and tablet. }\end{array}$ \\
\hline 4 & $\begin{array}{l}\text { Presentation/ } \\
\text { Exhibition }\end{array}$ & 1 Day & $\begin{array}{l}\text { 1. Presenting and constructing the learning content, } \\
\text { 2. Actively involved in the learning process, } \\
\text { 3. Explore and experience the AR model via } \\
\text { smartphone and tablet. } \\
\text { 4. Share the learning content on social media }\end{array}$ \\
\hline
\end{tabular}

\section{RESULTS AND DISCUSSION}

This research quantifies qualitative data obtained from the open-ended survey, which was posted online via a special discussion group in Facebook, with exclusive members of those who enrolled in Building Construction and Materials 3 Class (BCM3). Students' feedback was sought after they completed the projects, particularly on their impression towards the project. The collected verbatim data were analysed using qualitative methods of content analysis, where the frequency of coded factors would be quantified to 
produce an empirical result. The analysis is divided into two parts, which are demography of the respondents, and students' impression towards the AR implementation.

\subsection{Demography of the Respondents}

Out of 101 students enrolled in the class, only $76 \%$ of the total number of students responded, which made the total number of respondents as $77(n=77)$. Among the respondents, 40 of them are male students $(52 \%)$, and 37 are female students (48\%). The majority (97\%) of the respondents are in their second year of study, and another 3\% are third-year students.

Using qualitative data analysis software, the demography of respondents is termed as Primary Documents (PD), who have been divided into groups depending on their skills of developing 3-Dimensional computer generated architectural models. The level of skills is categorised as very good, good, satisfactory, poor and very poor. The division is done to enable researchers to correlate the data in the analysis process. Among the respondents, only $3 \%$ have rated themselves as very good in developing 3-Dimensional computer generated architectural models, $10 \%$ rates as good, and $27 \%$ consider themselves as having a satisfactory level of the skill. Meanwhile, $42 \%$ have rated themselves as poor in developing 3-Dimensional computer generated architectural models, and 18\% stated they are very poor for such skill. Table 2 shows the students' self-rated 3-D skill.

Table 2 Students' self-rated 3-D skill

\begin{tabular}{|c|c|c|c|}
\hline No & $\begin{array}{c}\text { 3-Dimensional computer } \\
\text { generated architectural models }\end{array}$ & Frequency & Percentage \\
\hline 1 & very good & 3 & $3 \%$ \\
\hline 2 & good & 8 & $10 \%$ \\
\hline 3 & satisfactory & 21 & $27 \%$ \\
\hline 4 & poor & 32 & $42 \%$ \\
\hline 5 & very poor & 14 & $18 \%$ \\
\hline & TOTAL & 77 & $100 \%$ \\
\hline
\end{tabular}

\subsection{Impression on the AR Implementation}

Based on the 77 collected responses, there are 109 quotations derived from the open-ended question on respondents' impression towards the AR Implementation. The analysed codes are grouped in three (3) principal codes, which are the Learning Content (6 quotations), Positive Feedback (86 quotations), and Negative Feedback (17 quotations). Table 3 shows the summary of analysed codes and quotation.

Table 3 Analysed Main Codes on Respondents' Impression Towards AR Implementation

\begin{tabular}{|l|c|c|c|c|}
\hline \multirow{2}{*}{ Primary Documents } & \multicolumn{3}{|c|}{ Main Codes } & \multirow{2}{*}{ Total } \\
\cline { 2 - 5 } & $\begin{array}{c}\text { Learning } \\
\text { Content }\end{array}$ & $\begin{array}{c}\text { Positive } \\
\text { Feedback }\end{array}$ & $\begin{array}{c}\text { Negative } \\
\text { Feedback }\end{array}$ & \\
\hline 3-D skill -very good & 1 & 10 & 2 & 13 \\
\hline 3-D -skill good & 1 & 43 & 9 & 53 \\
\hline 3-D skill - satisfactory & 4 & 19 & 5 & 28 \\
\hline 3-D skill -poor & 0 & 1 & 0 & 1 \\
\hline
\end{tabular}




\begin{tabular}{|l|l|l|l|l|}
\hline 3-D skill -very poor & 0 & 13 & 1 & 14 \\
\hline TOTALS & 6 & 86 & 17 & 109 \\
\hline
\end{tabular}

\subsubsection{Learning Content}

In the Learning Content main family code, respondents give only six (6) feedback. Five out of the six respondents offer views on software. A respondent narrates that "it is good that we learn to make model software like sketch-up and AR-media, which could be applied to design subjects." Another respondent agrees by stating that, "the concept of bringing AR into syllabus was great, definitely one of the unique things I have tried during studying". However, the second respondent also comments that some of the students are still lacking in computer-generated drawing skills using the drawing software; hence, fewer construction details could be shown in their work presentation.

Three other respondents express similar views on the complication of using the software. One of them highlights both processes of installing the software and converting sketch-up models to AR models are complicated. The other respondent expresses the concern on the difficulty to download big bite AR files of more than $6 \mathrm{MB}$ that students eventually must resolve with small size AR models. Another respondent views the process of getting AR mode is not time and user-friendly, because "many apps need to be downloaded first, and the wrong app leads to failure to get into AR, especially QR code reader". Hence, the respondent suggests that it would be much better if one app could have all the required features.

One respondent gives a remark on standardisation. The person addresses the need to standardise the size of AR models. Nevertheless, this remark is irrelevant because computer generated construction models are drawn using one to one scale (1:1 scale). Hence there is no issue of scale standardisation. However, this remark shows that despite the rigorous process of learning AR application, there is a student who still does not grasp the differences between virtual construction AR-model versus physical construction models.

\subsubsection{Positive Feedback}

The analysis shows that 86 out of 109 quotations from the respondents gave positive feedback on the impression of the implementation, which is amounting to $79 \%$. However, there is co-occurrence on the themes of quotations; hence, the total quotations become 88. Fig.2 shows the Positive feedback coding family, consisting of 8 themes; (1) experience, (2) practicality, (3) technique, (4) greatness, (5) effectiveness, (6) interesting learning, (7) satisfaction, and (8) cheap cost.

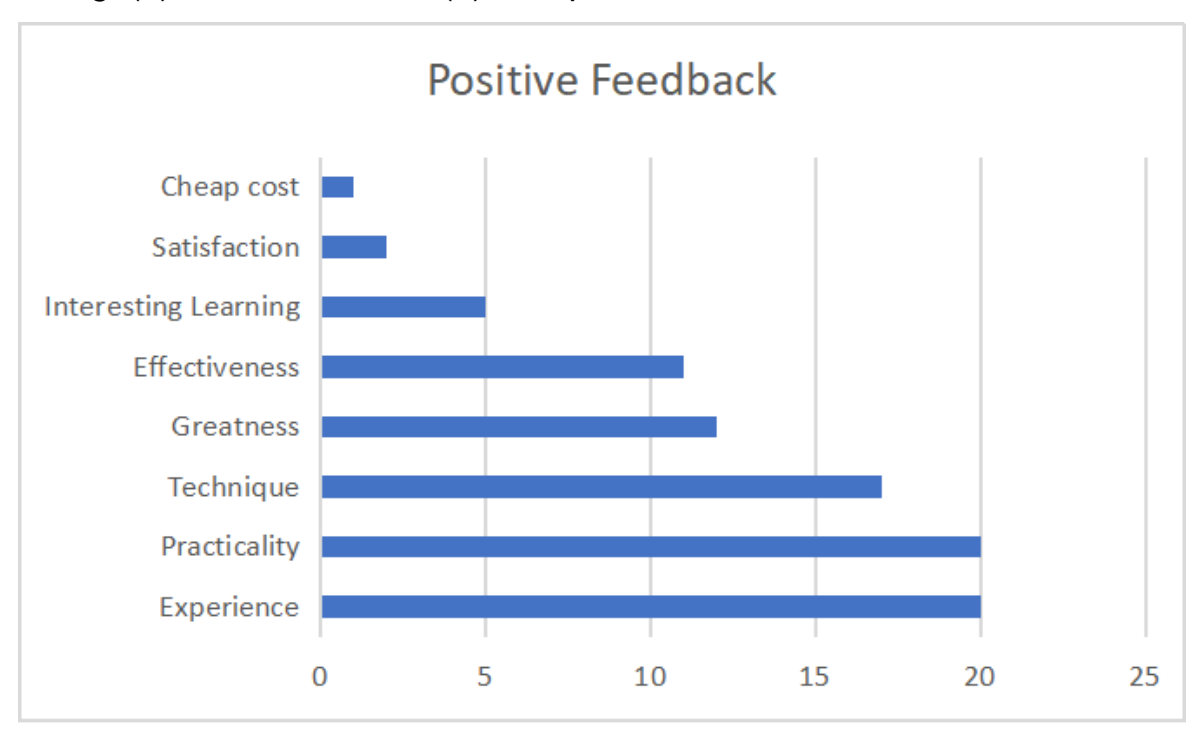

Fig. 2 Collected Positive Feedback

The most glaring and salient emergent theme is on respondents' experience. There are 20 quotations gathered from the primary data that relate to the experience theme. 6 out of the 20 respondents state that the exercise is fun and enjoyable, while four respondents mention that the exercise gives them a good experience. 3 out of the 20 quotations suggests about the "great" experience the respondents have had when exploring the exercise of using AR application. One respondent narrates that the activity is "a great 
experience for me where I learn a lot because I can see the construction methods and how elements are connected with each other". 4 respondents mention that the AR exercise provides a new approach of learning experience, makes them explore more, allows for self-learning, and gives opportunity to discover new technology. Meanwhile, three respondents state that the application of AR is to provide them with a "new" experience.

Practicality is another salient emergent theme that scores 20 quotations. Six respondents give remarks interm of AR application. 2 of the respondent state about the uniqueness of AR application, two respondents mention on the good 3-D architectural representative and one states about the easy mobility of virtual AR models. Another six respondents suggest the AR application in-term of instructional design. They perceive that this type of assignment involves practicality, more useful, and more beneficial for students, as compared to classes that discuss theory alone. They also view that this type of lecturing (instructional design) should be kept and applied to architecture design studio as well so that less printing is needed. One respondent states that the AR application could help students to do architectural design in "a better way'.

Meanwhile, eight respondents narrate on the students' understanding of AR application. 2 of the eight respondents mention that by using the system, the subject becomes easier, and they could understand the subject better. Three respondents state the AR application make learning more flexible because the AR models could be visualised in any scale. Meanwhile, three other respondents narrate that using AR application is a practical way to learn building construction because the AR models are very informative and could be visualised in 3-dimensional views.

The technique is another sub-theme that is worth mentioning in this result findings. There are 17 quotations gathered from the primary data that relate to technique theme. 7 out of 17 respondents in the technique theme positively describe the AR application as either great way, good way, new way, better way or nice way of learning construction in architecture education. Meanwhile, 5 of the respondents are in favour of the AR application by stating that the system enables them to practically "learn, explore and apply" new software and technologies. Three of the respondents have parallel views that AR application in architecture education enhances their learning and working on multimedia skills because it is easier to visualise 3-D design presentation using the system. Besides, two other respondents complimentarily support the notion by stating that using AR application is "a good step into learning structural and construction techniques" and "the technique had to be found".

Eleven respondents describe on the Effectiveness of AR application in architecture construction education by using the words of brilliant, beneficial, helpful, effective, good module, new knowledge, and will never be forgotten. Four of them elaborate that $A R$ application is good for understanding both visually and technically; AR helps to visualise in 3-dimension; AR should be included in the syllabus so that students could easily learn and understand 3-D forms, and integration of AR in an assignment is more practical rather than just learning theory.

In Greatness theme, 12 respondents generally describe that the AR application in architectural education is "great', while in learning theme, five respondents narrate that learning using AR application is interesting. Interm of satisfaction, two respondents mention that they are satisfied with the assigned works because "everything is so clear". Lastly, only one respondent mention cost, stating that the AR application cuts the cost by not having to build a physical architecture model. Overall, all the positive feedback from the 86 quotations are in favour of the AR application in building construction course.

\subsubsection{Negative Feedback}

Only $17 \%$ of the quotations is negative feedback, and Fig. 3 shows the semantic linkages of the negative feedback. There are four comments made on the aspect of time. Respondents feel that they do not have enough time to learn everything, they spend too much time doing the exercise, and they also spend too much time learning to use sketch-up software instead of learning building construction. Another aspect that has four (4) negative comments is on the scope of critical learning. Two respondents feel that they focus on certain structural details only, one respondent feels that AR does not improve understanding of building construction, and one respondent thinks it is impossible to do the exercise individually. In term of visualisation, a respondent comments that visualising model via AR marker is not visually clear, one respondent states that using sketch-up without AR is better for learning, and another respondent thinks that showing model using mobile screen could not improve understanding. In-term of difficulty, one respondent states that the exercise is laborious, and another one says that it is difficult to find new construction details. In term of stability, one respondent writes that the digital AR models are not stable and consistent. On other aspects, one respondent mentions that the 3-D AR models on markers are not clear, and one respondent 
states that the exercise is complicated.

Fig. 3 Semantic linkages on the negative feedback

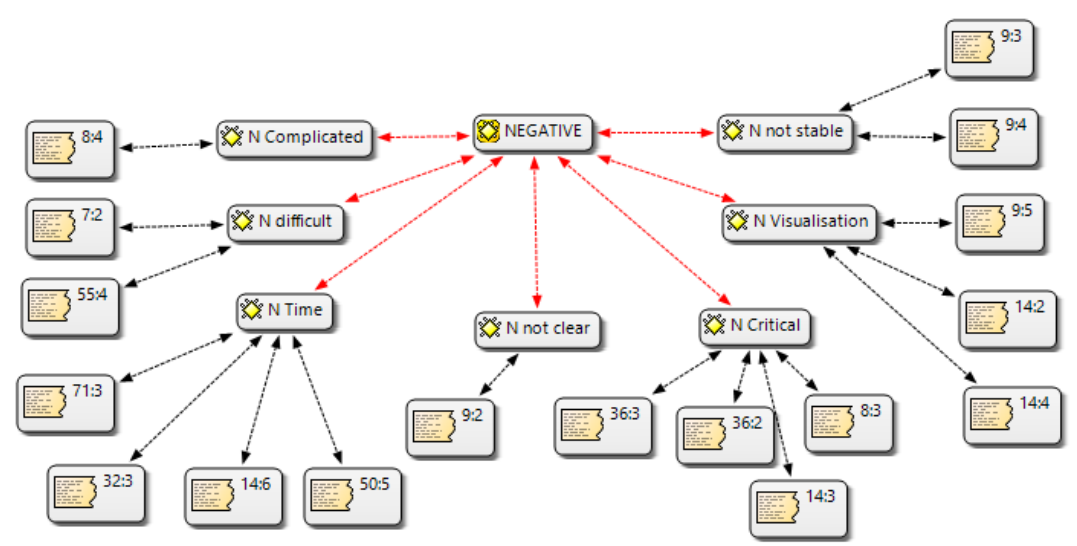

\section{CONCLUSION}

This study has examined students' insights on their experiences of AR exploration, where they have actively learned through playing, experimenting, socialising and collaborating with their peers. The study concludes that students who involved in the exploration of Augmented Reality Application believed that the application had enhanced their learning experience in positive ways, ranging from providing great, practical, effective, interesting, to a satisfactory learning experience. The AR application had also offered them to have very practical and economical techniques of active learning, with the merger of ICT and online conveniences. Thence, researchers perceive that the AR application should be further implemented in other subjects of architecture education.

\section{REFERENCE LIST}

Abdullah, F., Kassim,.H., Sanusi, A.N.Z., Tidjani, A.A., (2018). Experimenting Technology Enhancement Active Learning with Support of Mobile Device, Gamification and Augmented Reality Application. Advanced Science Letters, Volume 24 (11): pp. 7871-7875

Azuma, R., et al., (2001). Recent advances in augmented reality. IEEE computer graphics and applications, Volume 21(6): pp. 34-47.

Brown, T.H., (2005). Towards a model form-learning in Africa. International journal on eLearning, Volume 4(3): pp. 299.

Cheng, K.-H. and C.-C. Tsai, (2013). Affordances of augmented reality in science learning: Suggestions for future research. Journal of Science Education and Technology, Volume 22(4): pp. 449-462.

Cochrane, T. and R. Bateman, (2010). Smartphones give you wings: Pedagogical affordances of mobile Web 2.0. Australasian Journal of Educational Technology, Volume 26(1)

Greenhow, C.,(2011). Youth, learning, and social media. Journal of Educational Computing Research, Volume 45(2), pp. 139-146

Kassim, M.H., Abdullah, F., Sanusi, ANZ, (2018). Mobile Augmented Reality Learning: Design Exploration Toward Student Learning Trends. Advanced Science Letters, Volume 24(11): pp. 7890-7894

Lévy, P., (2001). Cyberculture. U of Minnesota Press, Vol. 4

Pang, L., (2009). A survey of web 2.0 technologies for classroom learning. International Journal of Learning, Volume 16(9)

Rahman, SM Niazur, Tanbira Alam, Nazmun Nahar Alam, Mohammad Ziaul Haque, and Tanjeda Alam, (2017). Medical Undergraduates Preference in Learning Style: A Single-Institute Experience from Bangladesh. Kuwait Medical Journal, Volume 49(1), pp.12-16

Sharples, M., Taylor, J, Vavoula, G., (2010). A theory of learning for the mobile age, in Medienbildung in 
Neuen Kulturräumen. Springer, pp. 87-99

Shuler, C., (2009). Pockets of potential: Using mobile technologies to promote children's learning

Sanusi, A.N.Z., Abdullah, F., Kassim, M.H., Tidjani, A.A., (2018). Architectural History Education: Students' Perception of Mobile Augmented Reality Learning Experience. Advanced Science Letters, Volume 24(11): pp. 8171-8175

Vavoula, G., et al., (2009). Myartspace: Design and evaluation of support for learning with multimedia phones between classrooms and museums. Computers \& Education, Volume 53(2): pp. 286-299. 